tho ligaments is absolutely futile as a mechanical procedure. Natural cicatricial tissue, allowed to mature without being stretched, is the only reliable means of repair.

\section{Fracture of the Spine of the Tibia.}

The mechanism of this accident appears to be the following. The knee is subjected to violent torsion, such as might produce a dislocation or rupture of the crucial ligaments; at the time when the force is applied the condyle of the femu: grinds across the surface of the tibia, and the sharp intercondylar margin shears off the spine. In some cases avulsion of the spine occurs instead of rupture of the crucial ligaments. The displaced fragment of bone may be lodged in the front part of the knee-joint, and so prevent its full extension. Diagnosis is verified by $x$-ray examination.

Symptoms.-The most constant symptom is a somewhat rigid block to full extension, usually accompanied by pain belind the patella.

Treatment.-If the knee can be fully extended the displaced fragment of bone being presumably pushed back somewhere between the condy!es, the knee should be fixed in this position for a long period to allow the torn structurés to reunite. On the other hand, if the displaced frag-

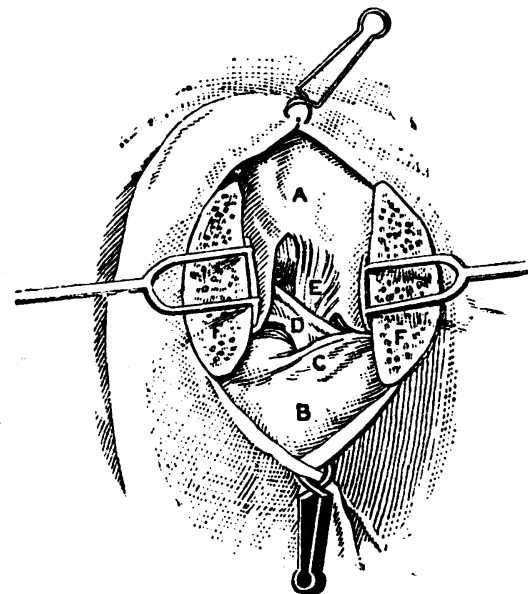

Frg. 2.-Showing patella sp:it. A, Femur; $\mathbf{B}$, tibia ; $\mathbf{C}$, transverse ligament ; $\mathbf{D}$, anterior crucial ligament; 1 , posterjor crucial lige ment; $F$, cut halves of patella. ment blocks ex. tension, and the surgeon cannot manipulate it back into a harm. less position, or extend the linee even by moderate force, it is best to remove the obstructing frag. ment of bone, fixing the lnee afterwards in a straight position, and leaving Nature to effect her own repair. The surgeon must use his ow $n$ judgement as to the route he adopts : the freest access is obtained by split. ting the patella longitudinally (Fig. 2), but if the $x$ rays show that the offending fragment of bone could be reached by an incision at the sicle of the patella, this is a less severe method of procedure. As I am largely responsible for the split patellar ronte in dealing with unusual derangements, I am anxious to empliasize that it is only needed in exceptional cases.

Thichened Retro-patellar Pads of Fat.

Almost any injury of the knee which is associated with increased vascularity or bruising may give rise to swelling of the pad of fat situated behind the patellar ligameut. Consequently this fat is liable to be nipped in full extension of the kuee. In ordinary civil life, this forms one of the varieties of the initial stage of a local monarticular rheumatoid arthritis. The condition, howerer, is in no sense rheumatic. The patient complains of pain and tenderuess in the knee after walking, and especially when going up and down stairs, or when getting up suddenly fro:n a chair after sitting for any length of time. The condition is maintained by the repeated small injuries which occur every time the lnee is fully ex. tended. The treatment, therefore, is obviously to prevent the patient from inflicting small bruises on the tender fat and its covering of synovial membrane. This can easily be done by putting a cork pad, half an inch thick, inside the boot under the heel, to prevent the complete extension of the knee during walking, and by fitting the knee with a cage support (Fig. 3), which allows full flexion but limits extension by about 30 degrees. Wearing this boot and cage splint the patient cannot fully extend the joint and in this way bruise the post-patellar fat. The swelling gradually disappears, and after a few weeks full extension can be performed without pain. The diagnosis of this condition is easy. The patient complains of pain in the knee, or, more often, in the front of the knee, not at the inner side. Passive extension of the knee by the surgeon produces the pain, which is definitely localized just below and behind the patella. On palpation the thickening of the pad of fat may be felt; it is enlarged and tender. but there is no sepsitiveness over the internal cartilage or the in. ternal lateral ligament. In some instances the retropatellar pad of fat may be bruised in common with injury to the semilunar cartilage. The full tender point of the internal lateral ligament, cartilage, and fatiy pad will be found in such a case.

In all the injuries of the linee which I have been discussing wasting and wealrening of the quadriceps muscle is a characteristic feature, and no treatment can be regarded as sufficient which does not provide for the restora tion of the efficiency of this muscle during the stage of convalescence. This is particularly to be noted in the condition

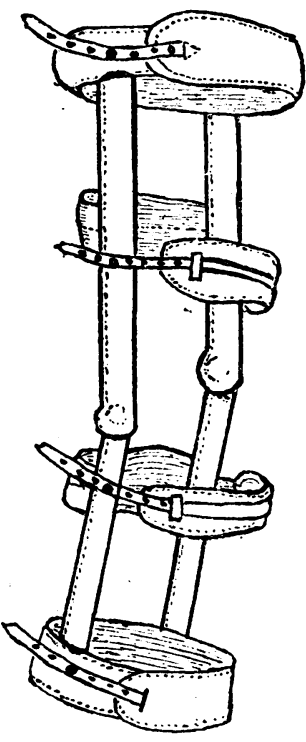

Fig. 3.-Cage support for which is now under discussion, for some of the deep short fibres of the subcrureus muscle are inserted into the synovial membrane of the joint, and when they contract they draw up the synovial membrane and help to pull the pad of fat out of danger when the knee is extended. Neglect, therefore, of the quadriceps muscle will leave the patient peculiarly liable to a recurrence of the injury

If the reader has appreciated the regular gradation of disorder's of the knee already described, he should have little difficulty in applying and adapting the method of diagnosis and treatment to unusual types which occur as a result of injuries in military service. Even: bullet wounds through the joint, which sometimes chip off fragments of bone, can be dealt with on lines similar to those indicated for fractures of the spine of the tibia. The whole question of septic arthritis in and about the joints, with resulting ankylosis, is a larger subject, which cannut be dealt with in the present article.

\section{FURTHER OBSERVATIONS}

\section{ON THE TREATMENT OF GAS GANGRENE BY THE INTRAVENOUS INJECTION OF HYPO- CHLOROUS ACID (EUSOL). \\ $\mathbf{B Y}$}

C.aptain JOHN FRASER, M.D., M.Ch., F.R.C.S., R.A.M.C. ASSISTANT SURGEON, ROYAL HOSPITAL FOR SICK CHILDREN, TDINBTRGE,

AND

Captain H. J. BATES, B.A., M.B., B.Ch.Dubl., R.A.M.C.T.(F.),

BRITISH EXPEDITTONARY FORCT.

(Report to the Medical Research Committee.)

In the British Medical Journal (1916, i, 83) we published a series of cases giving the results of treatment of the toxaemia of gas gangrene by the intravenous injection of hypochlorous acid. We have now had further experience of this metinod of treatment, and we submit the results which we have obtained.

CASE I.

Corpl. G. S. (Chart 1). Admitted January 28th, 1916, at 1.30 a.m., having received a bullet wound of the right forearm on the previous day. On being examined under chloroform at 9 a.m., the arm was found to be extensively infected with gas gangrene. This was spreading upwards along the brachial 
artery to beyond the bend of the elbow. The wound was opened up and drained with a rubber tube, and a free incision

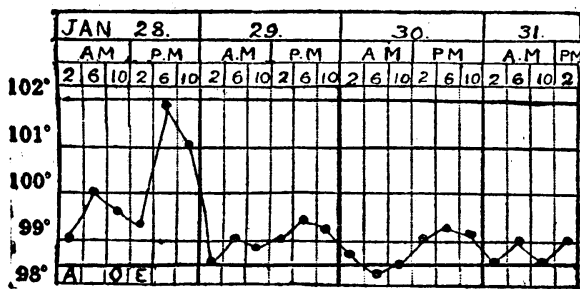

Chant 1.-A, Admission. O, Operation: gas

found intravenously at 2 p.m. E, Eusol, 50 c.cm.

CASE Ir.

Pte. H. (Chart 2). Admitted January 27th, 1916. The patient suffered from a severe compound fracture of the left ankle, the bones being apparently badly damaged; the blood vessels, however, were not specially injured.

He was operated on immediately after admission, when it

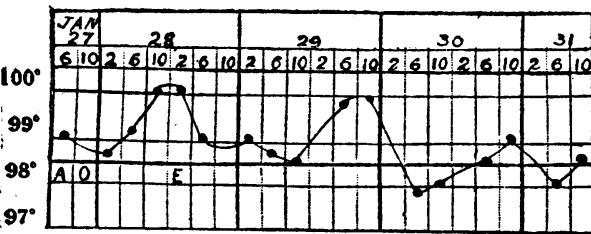

Chart 2. - A, On adrnission, 5 p.m. o, Operation 5.30 1.m. E, Eusol intravenously, 20 c.cm. sary to remove a considerable amount of bone. The partly closed partly closed On the fol. lowing day the patient's general .congood, there being restlessness and irritability, and a slight tendency to rise of temperature. On removing the dresging. the foot was found to be infiltrated with gas, the crepitation being especially marked round the malleoli and the blood vessels. Several sutures were removed and free ind the blood made into the gas-infected areas ; $25 \mathrm{c.cm}$. of eusol were given intravenously at 2 p.m.

The patient made a good recovery, there being no further sign of gas production.

CASE III.

Pte. C. (Chart 3). Admitted January 20th, 1916, having received extensive and severe wounds of both thighs two days previously. The condition of the right thigh was especially bad; the femur was probably fractured, and the soft tissues were distended with gas. In the left leg there was a wound of the soft tissues, and this was slightly infected with gas. The

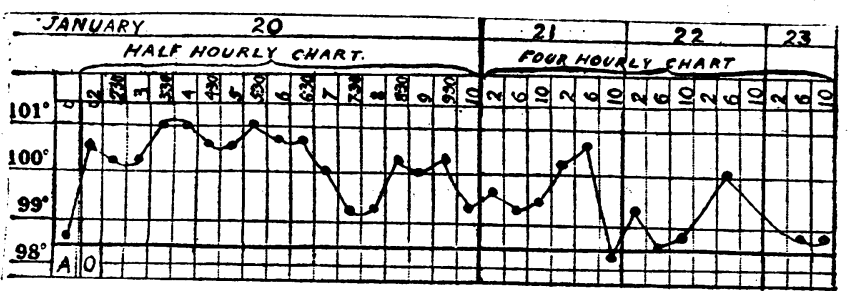

Chant 3.-A, On admission. o, Operation of eusol intravenously, $70 \mathrm{c.cm}$.

general condition of the patient was unsatisfactory, there being signs of commencing gas toxaemia.

An operation was at once performed, the tissues being thoroughly opened up and drained; at the same time $70 \mathrm{c.cm}$. of eusol were given intravenously.

The patient made an excellent recovery, and there was no further evidence of gas production subsequent to the operation. CASE IV.

Corpl. A. Admitted January 24th, 1916, suffering from a Ane temperatare was 99.6 $\mathrm{F}$., and an operation was per. formed at 6 p.m. The fragment of metal causing the condition was however, not found. Within a few hours the temperature began to rise, until it reached $106.5^{\circ} \mathrm{F}$., and following morning. No eusol was following

At post-mortem examination it was found that the brain rvas in fected with a gas-producing orgauism. The gas was accumulating even in the space between the dura mater and the bone. This apparently was the cause of death.

CAse v.

Pte. C. Admitted January 24th 1916. This man had been severely wounded in the right leg and thigh by a shell explosion, the soft tissues being extensively torn and infected with mud. the brachial artery at the bend of the elbow ; 50 c.cm. eusol were injected intravenously at 2 p.m.

patient made an excel lent recovery there being no further evidence of the production of gas

The case presented some difficulty, as, although no actual gas production was observed in the tissues, the patient's genera condition on the second day resembled the toxaemia we have become familiar with in cases of gas infection. On the night of January 25th, when the patient was almost pulseless, received, at our suggestion, $50 \mathrm{c.cm}$. of eusol in $200 \mathrm{c.cm}$. saline. He, however, died about one hour later.

On considering this case we have arrived at the conclusion that it was not one of gas infection.

\section{CASE vi.}

Pte. D. (Chart 4). Admitted February 20th, 1916. There was a shrapnel wound behind the righ knee, and the femoral artery was divided. The leg below the knee was, on admission, greatly swollen with gas. In addition there were wounds of the left leg and buttock and also of the face and head. The general condition was bad there being considerable toxaemia. At 2 a.m. the right leg was amputated at the knee, and $60 \mathrm{c.cm}$. of eusol were given intravenously. Within six hours of the injection the pulse slowed to 112 ; at 3 p.m. it was 116 . The temperature and pulse now, how ever, began to rise steadily, and at $10 \mathrm{p.m}$. the temperature was at 10 p.m. the temperature was the following day the condition

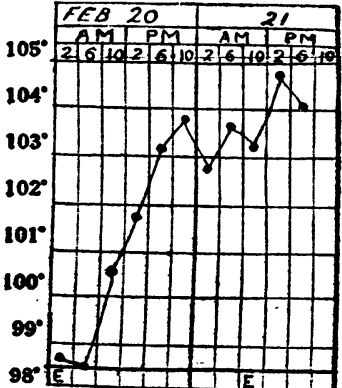

CaArt 4.-E, Eusol, 60 c.cm. ntravenously. was much worse, and at 10 a.m. a second intravenous injection of $60 \mathrm{c.cm}$. of eusol was given. This was followed by a slight reaction. The temperature rose to $105^{\circ} \mathbf{F}$, and the patient diod at 6 p.m.

Case vir.

Pte. E. (Chart 5). Admitted (under the care of Captain Bates) February 28th, 1916. On admission, there was found to be a bullet wound of the posterior part of the right thigh; this was associated with a compound fracture of the femur. but no large vessel was injured. Though the patient was admitted within four hours after being wounded, the development of gas within four hours after being wounded, the

The wounds were opened up, douched with eusol, and drained.

Fragments of loose bone were removed, and several counter opeuings were made to secure free drainage. The patient had an uncom. fortable night, and at 6 a.m. February 29 th the pulse suddenly rose from 92 to 130 . There was increasing restlessnes of commencing toxaemia. At 10 .m. the pulse was 136, and at 11 a.m. free incisions were made and on injection of $60 \mathrm{c.cm}$. of eusol in saline was given. There was very little reaction after this procedure; the pulse inoreaced elightly, and in the afternoon the fall Therature was inclined to was administered subcutaneously and by the rectum, and adrenalin was given in 10 and $15 \mathrm{~m}$ doses.

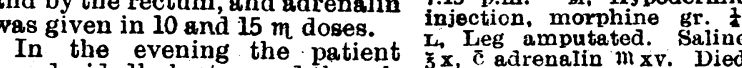
was decidedly better, and though $\bar{\xi} x$, c adrenalin $M x v$. Died the pulse was scarcely perceptible

he passed a comfortable night. On March lst the temperature had fallen to normal, and it was thought that there was a distinct improvement in the general condition. The leg, however, was rapidly becoming gangrenous, and thus the question arose whether it was not advisable to take advantage of the improvement to remove the limb. It was decided to do this. The operation was performed at 11 a.m and the patient stood it wonderfully well. Within half an hour of its conclusion he was sufficiently recovered to take some stimulant. In the afternoon how recoved to take som suddenly, and died at 2.30 p.m.

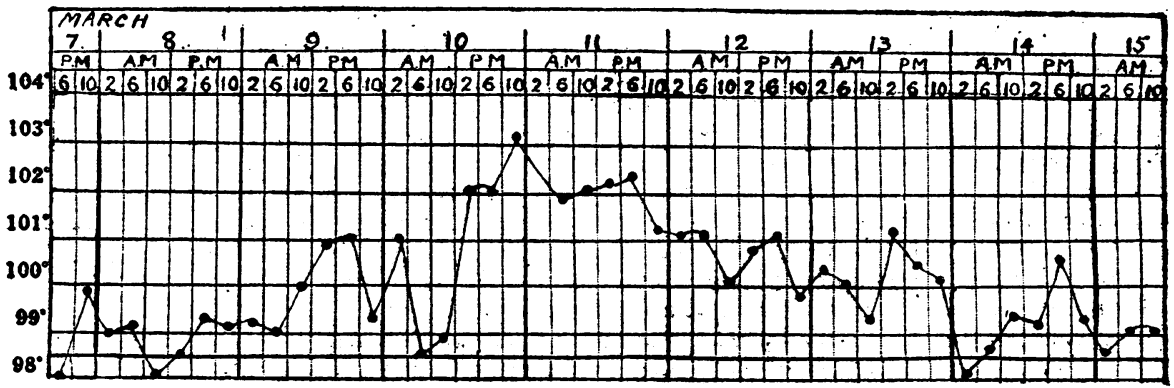

Chart 6.

Pte. J. F. (Chart 6). Admitted Maroh 7th, 1916, having been wounded by a shell the same day. There was extensive 
laceration on the outer side of the right thigh; the femur was fractured, but the large vessels were not involved. The whole wound was infected with gas, and the muscles were crackling with it. There was also already evidence of commencing gas toxaemia.

The patient was operated upon at 5 p.m. on March 7 th. The wound was opened up, the bones were placed in apposition drainage was secured, and the whole wound thoroughly washed out with eusol. Immediately after the operation $75 \mathrm{c.cm}$. of eusol were given intravenously. There was an immediate reaction; the pulse rising within the following three hours to 140.

On March 8th there was some evidence of gas on the inside of the leg, but no sign of a spreading condition. By $10 \mathrm{a} . \mathrm{m}$. the pulse had fallen to 108 , but in the evening it rose again to 140 . phe limb was dressed every four hours, day and night.

The limb was dressed every four hours, day and night.
On March 9th the condition in the morning was somewhat On March 9th the condition in the morning was somewhat
better, but during the evening a relapse took place. Sickness came on, and there was suppression of urine. Two pints of came on, and there was suppression of urine. Two pints of similar quantity during the following night. The patient received two ounces of champagne every four hours.

On March 10th the condition was much improved in the morning; the temperature fell to normal, but in the afternoon again reached $103^{\circ} \mathrm{F}$. The general condition was, however, good. The patient complained of pain in the left axilla, at the site of the last saline injeotion. On March 11th and 12th the general improvement was maintained, the temperature falling steadily."

On March 13th an abscess in the left axilla was opened, and a quantity of thin, foul-smelling pus was evacuated. Unfortunately, hovever, by an oversight, it was not examined.

Thereafter the patient made an uninterrupted recovery.

Of these eight cases, three call for special comment. In Case IV, at the time of the operation evidence of the presenee of gas gangrene was not present, and therefore treatment by hypochlorous acid was not applied. There is no doubt, however, as was shown by the results of the post-mortem examination, that during the ten hours succeeding the operation a gas-producing organism had been at work in the brain. The rapidity of the fatal issue may to some extent be explained by the origination by the bacterial products of mechanical effects such as so frequently play a part in ordinary infections of the brain and meninges. Case v also presents points of interest. Although from the clinical observations the patient's condition sug. gested a gas gangrene toxaemia, no evidence of infection with organisms of gas gangrene was available, and we are therefore of opinion that some other factor must have been at work in the patient. In Case vir, although death occurred, there was definite evidence that the treatment with hypochlorous acid had a beneficial effect; in fact, it was the improrement which occurred, and which we attributed to the treatment, that led us to undertake the amputation of the gangrenous limb. We are in. clined to attribute the death to the shock of the opera. tion which was perforned. Looking at the series of cases as a whole, and excluding Case v, where evidence of the presence of gas gangrene was wanting, and Case Iv, in which eusol was not given, we found that in four cases where evidence of serious toxaemia existed improvement and ultimate recovery followed the adminis. tration of. hypochlorous acid. The other two cases resulted in death, but, as alieady stated, in one of these definite improvement followed on the treatment which was adopted. Thus there remains only one case in which the failure of the treatment has not been explained.

Our further experience of wounds which become infected with the organisms of gas gangrene confirms the view ex. pressed in our previous paper that the absorption of toxic products from the gangrenous tissues constitutes a serious menace to life. The bacteriological data do not as yet justify the position that the earlier symptoms of a general effect on the body are due purely to the absorption of poisons from the original site of bacterial infection. There can be little doubt, however, that the organisms concerned in the disease do produce definite toxins, as has been shown by the work of Weinberg and Séguin and others. Our experience justifies us in saying that the effects of these toxins can be combated by the use of hypoclllorous acid, and when nentralization of these effects occur's the patient's body is in a better position to throw off the infection. The recognition that a patient is suffering from the absorption of toxic products to a dangerous degree must obviously rest upon clinical observations, but we think that those who have had experience in the field will admit that the recognition of a danger point in a patient's condition is possible. The appreciation of an improvement in a patient's state must also rest upon clinical experience.
Sometimes it is reflected in a slight rise in temperature, at other times in a rise in the pulse-rate; while in yet other cases an improvement in the general condition and appearance of the patient indicates that the danger from the toxaemia is passing off.

\section{CONVALESCENT PARATYPHOIDAL AND DYSENTERIC CASES CONSIDERED FROM THE PREVENTIVE STANDPOINT. BY}

T. WALKER HALL, M.D,

PROFESSOR OF PATHOLOGY, UNIVEISITY OY BRISTOL, IANORARY CONSULTING PATHOLOGIST TO THE 2ND SOUTHERN
GENERAI HOSPITAL;

Lieutenant D. C. ADAM, and R. E. SAVAGE, A.R.C.S., R.A.M.C., D.I.C.

(Report to the Medical Research Committee.)

THE period of convalescence which follows acute in. fections presents many features of interest. - It permits an insight into the severity of the infection, exhibits the results of the treatments adopted, and provides an oppor: tunity for detecting the persistence of the infective organism and for the segregation of temporary or possible permanent carriers of the infection.

In this laboratory a number of typhoidal and dysenteric convalescents have been examined during the last eight months, and a record of some of the findings and failures may prove of value to other workers.

The cases grouped themselves roughly into three batches. The first extended from September to December, 1915, and contained some acute and subacute infections. The second covered the period from December, 1915, to February, 1916, and comprised cases of early convalescence; while from February to May the men forming the group were to all intents fit again for work.

The main features may be summarized as follows: Paratyphoid Convalescents.

\begin{tabular}{lll|c|c|c}
\hline & & $\begin{array}{c}\text { No. of } \\
\text { Cases. }\end{array}$ & $\begin{array}{c}\text { Bacilli } \\
\text { Present in } \\
\text { Excreta. }\end{array}$ & $\begin{array}{c}\text { E. histolytica } \\
\text { Present in }\end{array}$ \\
\hline Period I & $\ldots$ & $\ldots$ & 297 & 3.7 per cent. & - \\
Period II & $\ldots$ & $\ldots$ & 156 & 1.3 per cent. & 10.06 per cent. \\
Period III & $\ldots$ & $\ldots$ & 217 & None & - \\
\hline
\end{tabular}

Dysentery Convalescents.
Number of cases
Bacilli present in excre
.. 605
Methods.
… 1.1 per cent.

The first investigation carried out in each convalescent case consisted of the (1) estimation of the agglutinin content of the blood, (2) the microscopical examination of the stools, and (3) cultural isolation from urine and faeces. In a number of instances blood films were obtained and counted; the results will form the subject of a further paper.

1. The agglutinin estimations furnished data for confirmatory diagnosis and indicated the method of enrichment which should be adopted in the examinations of the excreta. They were carried out to their end titre in each instance and included were carried out to their end titre in each instance and included tests for $B$. typhosus, B. paratyphosus A, B. paratyphosus B,
$B$. dysenteriae (Shiga and Flexner types). The macroscopic $B$. dysenteriae (Shiga and Flexner types). The macroscopic
method and the Oxford standardized emulsions, supplied by method and the Oxford standardized emulsions, supplied by the Medical Research Committee, were used throughout. Incubation at $52^{\circ} \mathrm{C}$. in a moist atmosphere for two hours was followed by standing at room temperature for twenty hours. The results were then read off and checked by a second worker.
2. The microscopical examination of the stools was carried out on the lines recommended by Wenyon and a record kept of all the protozoal forms observed.

3. For the isolation of bacteria three comparative methods were used:

(a) Enrichment Period: September to November, 1915.-The stool was emulsified and added to brilliant-green peptone solutions after Browning and his co-workers, or to dulcite peptone when the agglutinations indicated a paratypiosus B peptone when the agglutinations indicated a paratypiosus $\mathrm{B}$ infection. After twelve to twenty-four hours' growth, warmed
bile-agar and endo plates were spread. Twelve to twenty-fours bile-agar and endo plates were spread. Twelve to twenty-fours
later suspicious colonies were picked off and transferred to later suspicious colonies were picked off and transferred to
tubes containing glucose, or mannite, lactose, dulcite, gelatine; tubes containing glucose, or mannite, lactose; dulcite, gelatime,
milk. Those giving typical reactious twenty-four hours later milk. Those giving typical reactions twenty-four hours later
were asglutinated with specific serums, and when the result 